The Wilson disease gene is a putative copper transporting P. type ATPase similar to the

\section{Menkes gene}

P. C. Bull, G. R. Thomas, J. M. Rommens J. R. Forbes \& D. Wilson Cox

Nature Genetics 5, 327-337 (1993)

Fig. 4 Alignment of MNK and WC1 CDNAs. The location of the regions underlined in Fig. 3 are indicated for each cDNA (see legend to Fig. 3 for abbreviations). The relative positions of probes Mc1.a and Mc1.b and cDNA clones from $W c 1$ are indicated. Hydrophobic regions that are likely to form membrane spanning regions are shown in black. Other hydrophobic regions that might also form transmembrane regions are cross hatched. Hydrophobic regions indicated on the map of MNK are those proposed previously ${ }^{17,30}$. Insertions and deletions in the Wc1 sequence as compared to $M N K$ are indicated. Insertions are indicated with a vertical line. Deletions are indicated with a chevron. Correction: Note that Pt should read Td and $\mathrm{Tr}$ should read $\mathrm{Ch}$, as in Fig. 3 and text.

\section{A gene for Stargardt's disease (fundus flavimaculatus) maps to the short arm of chromosome 1}

J. Kaplan, S. Gerber, D. Larget-Piet, J.-M. Rozet, H. Dollfus, J.-L. Dufier, S. Odent, A. Postel-Vinay, N. Janin, M.-L. Briard, J. Frézal \& A. Munnich

Nature Genetics 5, 308-311 (1993)

An incorrect version of Fig. 3 appeared in this paper. The correct figure is reproduced below.

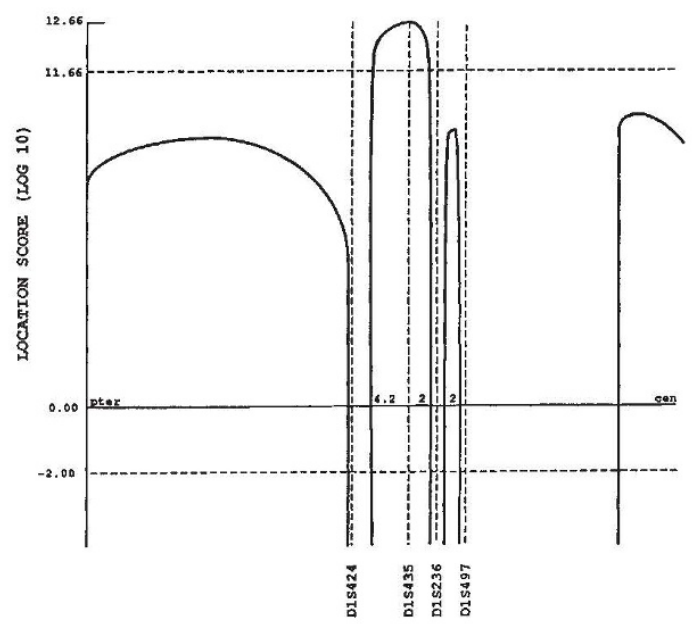

Reduced transcriptional regulatory competence of the androgen receptor in $\mathrm{X}$-linked spinal and bulbar muscular atrophy

A. N. Mhatre, M. A. Trifiro, M. Kaufman, P. KazemiEsfarjani, D. Figlewicz, G. Rouleau \& L. Pinsky

Nature Genetics 5, 184-188 (1993)

The acknowledgements that appeared in this paper were incorrect. The acknowledgements that were part of this paper are printed below.

Acknowledgements

We are grateful to D.S. Newman (Henry Ford Hospital, Detroit) and N. Azad (Ottawa General Hospital) for collection of original patient material. We thank L.K. Beitel for editorial advice and $R$.

Rosenzweig for secretarial assistance. This work is supported by grants from MRC Canada, FRSQ, Quebec, MDA of USA, ALS Society of Canada and the Canadian Network of Centres on Neural Regeneration and Functional Recovery. M.A.T. is a Chercheur Clinicien of FRSQ, Quebec.

\section{Fusion of a fork head domain gene to PAX3 in the solid tumour alveolar rhabdomyosarcoma}

N. Galili, R. J. Davis, W. J. Fredericks, S. Mukhopadhyay, F. J. Rauscher III, B. S. Emanuel, G. Rovera \& F. G. Barr

Nature Genetics 5, 230-235 (1993)

The Acknowledgements were accidentally omitted from this paper.

\section{Acknowledgements}

We thank J. Holick, S. Shane and L. Nycum for technical assistance. We gratefully acknowledge the advice and assistance of J. Biegel and D. Shapiro. This work was supported by grants from the National Institutes of Health, the W. W. Smith Charitable Trust, the Hansen Memorial Foundation, the Mary A. H. Rumsey Foundation and the Pew Scholars Program in the Biomedical Sciences.

The accession nos. of the sequences reported in this paper were printed incorrectly. Correct information follows.

The sequences reported in this paper have been deposited in GenBank (accession nos. U02308, U02309 and U02310). 